\title{
It's morning in America: la invasión de los ladrones de cuerpos como retrato de una sociedad ${ }^{1}$
}

\section{Roger Ferrer-Ventosa ${ }^{2}$}

Recibido: 2017-07-06

Enviado a pares: 2017-07-12
Aprobado por pares: 2017-09-12

Aceptado: 2017-09-14

DOI: 10.5294/pacla.2018.21.4.4

\section{Para citar este artículo / to reference this article / para citar este artigo} Ferrer-Ventosa, R. (2018). It's morning in America: la invasión de los ladrones de cuerpos como retrato de una sociedad. Palabra Clave, 21(4), 1023-1049. doi: 10.5294/pacla.2018.21.4.4

\section{Resumen}

El arte fantástico, como cualquier forma de arte, puede servir como reflejo de una sociedad o de un individuo, reflejo distorsionado, en el caso concreto de este género. En el artículo, analizaremos La invasión de los ladrones de cuerpos y sus sucesivos remakes; ellos han servido para mostrar el principal riesgo en las sociedades contemporáneas: la dictadura de la mayoría silenciosa o del pensamiento único. En las películas, unas vainas extraterrestres suplantan a la población; crean dobles físicamente idénticos de las personas, aunque sin emociones. Con ello, la sociedad pasa a regirse por un único principio, una voluntad unitaria que elimina cualquier disensión. Además, se postula que esa metáfora funciona adecuadamente para describir las sociedades posteriores a la Segunda Guerra Mundial, especialmente en aquellas

\footnotetext{
1 Realizado gracias a una ayuda FPU del Ministerio de Educación, Cultura y Deporte de España. Este artículo es resultado de algunas de las investigaciones realizadas para el proyecto sobre cine del Ministerio de Economía y competitividad español, HAR2015-66262-P.

2 orcid.org/0000-0003-2568-1271. Universidad de Girona, España. roger.ferrer@udg.edu
} 
más influidas por la revolución conservadora impuesta por Reagan y Thatcher. La principal novedad del texto radica justamente en trazar esa relación entre sociedades de las últimas cinco décadas con la serie de películas sobre los ultracuerpos. La propuesta parte del visionado de las cuatro películas, más una base teórica de referencias bibliográficas sustentada en cuatro principales líneas: la situación política y la teoría política y social en las últimas décadas; el cine fantástico y algunas de sus características; las relaciones entre sociedades y cine fantástico, entendido este como metáfora de aquellas; y el análisis de las películas de ultracuerpos. Sobre ello se sustentarán los puntos de vista defendidos en la reflexión.

\section{Palabras clave}

Ultracuerpos; ultraliberalismo; pensamiento único; totalitarismo (Fuente: Tesauro de la Unesco). 


\section{It's Morning in America: Invasion of the Body Snatchers as a Portrait of a Society}

\section{Abstract}

Fantastic art, like any form of art, can serve as a reflection of a society or an individual. In the specific case of this genre, it is a distorted reflection. The authors analyze Invasion of the Body Snatchers and its successive remakes, all of which have served to show the main risk in contemporary societies; namely, the dictatorship of the silent majority or a single way of thinking. In these films, extraterrestrial seed pods supplant the population and create physically identical duplicate replacement copies of each human, but devoid of all human emotions. With this, society becomes governed by a single principle, a unitary will that eliminates any dissent. Likewise, it is suggested this metaphor works adequately to describe societies after the Second World War, especially those more influenced by the conservative revolution imposed by Reagan and Thatcher. The main novelty of the text lies precisely in that it traces the relationship between societies during the last five decades and the movie series on ultra bodies. The proposal begins with a view of the four films, plus a theoretical base of bibliographic references founded on four key lines: the political situation and political and social theory in recent decades; fantastic cinema and some of its features; the relation between societies and fantastic cinema, understood as a metaphor of those societies; and an analysis of ultra body films. The points of view defended in the reflections are supported by these lines of thought.

\section{Keywords}

Ultra bodies; ultraliberalism; unitary thinking; totalitarianism (Source: Unesco Thesaurus). 


\section{It's morning in America: a invasão dos ladrões de corpos como retrato de uma sociedade}

\section{Resumo}

A arte fantástica, como qualquer forma de arte, pode servir como reflexo de uma sociedade ou de um indivíduo, reflexo distorcido, no caso concreto desse gênero. Neste artigo, analisaremos Invasion of the Body Snatchers e seus sucessivos remakes; isso serviu para mostrar o principal risco nas sociedades contemporâneas: a ditadura da maioria silenciosa ou do pensamento único. Nos filmes, alguns esporos extraterrestres suplantam a população; criam clones físicos das pessoas, mas sem emoções. Com isso, a sociedade passa a ser regida por um único princípio, uma vontade unitária que elimina qualquer dissensão. Além disso, prega-se que essa metáfora funciona adequadamente para descrever as sociedades posteriores à Segunda Guerra Mundial, especialmente aquelas mais influenciadas pela revolução conservadora imposta por Reagan e Thatcher. A principal novidade deste texto está justamente em estabelecer essa relação entre sociedades das últimas cinco décadas com a série de filmes sobre os ultracorpos. A proposta parte do visto nos quatro filmes, mais uma base teórica de referências bibliográficas apoiada em quatro principais linhas: a situação política e a teoria política e social das últimas décadas; o cinema fantástico e algumas de suas características; as relações entre sociedades e o cinema fantástico, entendido este como metáfora daquelas; a análise dos filmes de ultracorpos. Sobre essas linhas, serão justificados os pontos de vista defendidos na reflexão.

\section{Palavras-chave}

Ultracorpos, ultraliberalismo, pensamento único, totalitarismo (Fonte: Tesauro da Unesco). 


\section{Introducción}

Este artículo pone en relación una película fantástica, La invasión de los ladrones de cuerpos (Invasion of the Body Snatchers, Don Siegel, 1956), más sus tres remakes La invasión de los ultracuerpos (Invasion of the Body Snatchers, Philip Kaufman, 1978), Secuestradores de cuerpos (Body Snatchers, Abel Ferrara, 1993) e Invasión (The Invasion, Oliver, Hirschbiegel, 2007), con la sociedad de sus respectivas épocas, los avatares acaecidos en los Estados Unidos - y en menor medida en Europa - durante ese arco temporal. Más que proponer unas ideas políticas bien articuladas, este artículo intenta exponer unas ideas sugerentes que deben encuadrarse en los estudios culturales. Se plantearán algunos de los cambios en el contexto sociocultural que reflejan el espíritu de cada época, con su reflejo distorsionado en ese arte para grandes audiencias que es el cine (Kuhn, 1992, pp. 9-10), en alguna de sus obras fantásticas más destacadas.

En esas décadas, se ha producido la consolidación de una manera de concebir la economía, la política y la sociedad, que ha supuesto un cambio drástico en los valores culturales, algo que, entendemos, se ha reflejado en las películas; asimismo, esas películas han contribuido a modificar el imaginario en un sentido favorable a ese cambio de mentalidad. Por tanto, en el estudio, se analizarán estas cuatro películas, tomadas como termómetro cultural; además, servirán para indicar los deseos, los sueños y las frustraciones de cada época (Loock, 2012, p. 140). En esta propuesta, se trazarán paralelismos entre esas muestras de imaginario colectivo llamado cine fantástico con la mentalidad mayoritaria cuando se realizó cada película, una forma de entender el mundo y las relaciones sociales progresivamente hegemónicas.

El artículo sigue el ejemplo del teórico cinematográfico Sigfried Kracauer, quien en De Caligari a Hitler expuso los correlatos entre el triunfo nazi y el cine comercial alemán de la época, especialmente el de géneros, como el fantástico (perfecto para exponer contenidos subconscientes); también se sigue el ejemplo de ciertos estudios culturales que analizan el 
cine de ciencia ficción estadounidense de la década de 1950 interpretado bajo una clave psicológica y sociológica, como los dos clásicos citados en la bibliografía: Paranoia, the Bomb, and 1950s science fiction films, de Cindy Hendershot; y Alien zone: Cultural theory and contemporary science fiction cinema, editado por Kuhn.

Tras este breve apartado aclaratorio que expone lo que se propone con el texto, se esbozará el vínculo principal entre el marco cultural hegemónico con algunas de sus ideas básicas - mayoría silenciosa, consenso, pensamiento único y hegemonía- que permiten su comparación con la sociedad de los ultracuerpos, al menos para quien esto escribe. El arco temporal básico seleccionado se extiende desde finales de la década de 1970 a la crisis de 2008. Aunque las sociedades desde esta década son más complejas que la cuestión de su organización político-económica, sí que puede afirmarse que la hegemonía ultraliberal como discurso central ha existido, por una serie de razones que no conciernen a este trabajo, sino a uno de política o de economía. A continuación, se presentarán tres apartados para reflexionar sobre las cuatro películas que comparten villanos y gracias a las cuales sirve la analogía.

Finalmente, se incluirá un breve apartado tanto para resumir lo expuesto como para matizarlo, con nuevos argumentos que servirán de contrapeso y que también intentarán, incluso, justificar el porqué de esa tendencia del liberalismo a extremarse en ultraliberalismo.

\section{El presidente propone y la mayoría moral dispone: La invasión de los ladrones de cuerpos y sus remakes}

En 1978, Philip Kaufman rodó un remake del clásico entre los clásicos del cine paranoico, La invasión de los ladrones de cuerpos. La versión de la década de 1970 se tituló en el mercado español como La invasión de los ultracuerpos. Al contrario que la mayor parte de remakes, el de Kaufman ostenta una gran calidad y, con la versión original de Donald Siegel, constituyen dos de las mejores obras del fantástico, díptico centrado en lo que puede suceder si una sociedad se regula por el pensamiento único. Para Font, buena parte 
del cine fantástico posterior toma de las ideas contenidas en la obra de Siegel (2012, p. 41). Pero esa calidad cinematográfica no concernirá a este artículo, más interesado en cuestiones culturales y sociológicas.

Uno de los mensajes promocionales con que Ronald Reagan se presentó a las presidenciales para su reelección de 1984 afirmaba que una nueva era amanecía en los Estados Unidos; el actor de películas de serie B - alguna de ellas dirigida por el propio Siegel— se alzaba como defensor del ultraliberalismo máximo, aplicado en la primera potencia mundial, tras experimentos de laboratorio en diversas otras regiones, como el Chile de Pinochet - "De hecho, fue en el laboratorio chileno donde se experimentaron las fórmulas que aplicarían en sus países las grandes figuras del liberalismo neoclásico en la década de 1980: Margaret Thatcher y Ronald Reagan" (Veiga, 2009, p. 151) — o la Nueva York a finales de la década de 1970. "It's morning in America again", aseguraba el anuncio (https://goo.gl/6RF3M). Reagan lo conseguiría.

Pero ¿en qué consistía esta nueva era? Uno de los conceptos acuñados por Richard Nixon había sido el de la mayoría silenciosa, ese grupo de "decentes" ciudadanos que no están en favor del discurso más o menos permisivo política y moralmente; según Nixon, los puntos de vista de la mayoría silenciosa no aparecen reflejados en los medios (Scruton, 2007, p. 636). Retorciendo el significado de la mayoría silenciosa, y denotando un claro influjo de las teorías de la Escuela de Frankfort, podría entenderse como el resultado consensual generado entre una masa de población atónitamente colocada en una sobreestimulación de sensaciones e información, que la habría sumido en un letargo. Sobre esa masa resulta, entonces, más sencillo aplicar sofisticadas tácticas de marketing. Entre la mayoría silenciosa espectadora se promovió la idea de consenso y la de pensamiento único, dos de los puntales básicos para entender política y sociedad bajo el ultraliberalismo, al menos tal y como se entenderá en este artículo.

Bernay, uno de los más destacados y astutos innovadores en el sector de las relaciones públicas, describió el consenso como la esencia de la democracia (Chomsky, 2006, pp. 21-22); las relaciones públicas trabajarían en 
la propaganda para fabricar este estado colectivo, a las órdenes de quienes tienen recursos y poder para hacerlo, a saber, la élite financiera y empresarial. Para situar el pensamiento único, servirán las ideas de Ignacio Ramonet, quien lo define como la traducción a términos ideológicos de los intereses del gran capital, con dogmas tan férreos como que lo económico prima sobre lo político (2006, pp. 51 y ss.). Se formulan los conceptos de realismo y de pragmatismo, con el llamado fundamentalismo de mercado que asegura que este se autorregula, la competitividad como ley de relaciones sociales, el libre intercambio cuya consecuencia idealmente sería el crecimiento interrumpido o infinito, o la mundialización, la reducción del Estado hasta que se limite a tareas de orden público o la elusión de los conflictos ecológicos.

Otro de los eslóganes lanzados por los think tank del liberalismo entendido de esta manera, y propagados por los gabinetes de comunicación de los partidos mayoritarios, consiste en que el pensamiento único es lo lógico, lo razonable, sus propuestas son las del sentido común; deslizan subrepticiamente algunas ideas que rozan el totalitarismo, como un monismo filosófico que hace dimanar todo del centro hegemónico, la carencia de alternativas, el consenso regido por una supuesta mayoría silenciosa ... ideas presentadas como lógicas, razonables, el justo punto medio. Es más, son las únicas posibles, puesto que no existe alternativa razonable.

Sobre el totalitarismo, han existido diversas variantes, desde el fascismo al comunismo-estalinista, con investigadores que han encontrado lineamientos diferentes, pero en todas ellas se considera el control desde una estancia central, un rasgo común básico, a menudo mediante un partido (Scruton, 2007, p. 696). Tal y como entendemos esta organización social y política, la consciencia individual, la personalidad, las diferencias, quedan subsumidas en ese flujo general monista (Arendt, 1979, p. 249), la aspiración a una unicidad de la que parte todo, la voluntad del Reich o la de los mercados entendidos de una manera específica, sin posibles variaciones.

Amparados por esos grandes conceptos, muchos de ellos vacíos de contenido, con una aplicación a modo de sucedáneos, estos sectores han 
seguido políticas tendentes a mantener el statu quo, a asegurar aún más el poder y la riqueza de un porcentaje minúsculo de la sociedad, bajo la excusa de que así se enriquecía el común. Durante esos años se produjo una inaudita transferencia de riqueza de los sectores pobres a los ricos, lo cual incrementó la diferencia entre ambos sectores de la población.

Según datos aportados por Noam Chomsky, 70 \% del aumento per cápita durante las tres legislaturas consecutivas del binomio republicano Reagan-Bush se concentró en $1 \%$ de la cúspide social, mientras se desmoronaba el poder adquisitivo de la base (1996, p. 182). En 1996, el conjunto de la renta de $45 \%$ más pobre de la población era igual al de las primeras 358 fortunas (Harvey, 2009, p. 42). Y, lejos de mejorar, esa situación se ha acentuado desde la crisis de 2007-2008. ${ }^{3}$ El ultraliberalismo es el responsable, con sus tesis favorecedoras de las desigualdades sociales y la injusticia estructural acentuada.

El otro motivo recurrente para aplicar las políticas ultraliberales ha sido justificar sus acciones más impopulares en la inexistencia de otras alternativas, previamente ridiculizadas, con el célebre eslogan TINA de Margaret Thatcher, “There is no alternative”, en lo que podría definirse como un monismo epistemológico con derivadas políticas, económicas y sociales.

Finalmente, la última idea básica que se pretende subrayar para establecer el marco teórico radica en la dimensión mediática, que modula los discursos y construye imaginario. Resulta aconsejable no menospreciar el papel de los poderes mediáticos y de las industrias culturales en este proceso. Sobre los discursos dominantes, se sigue en buena medida la teoría sobre ellos de Foucault en Las palabras y las cosas, con ellos que controlan el espíritu de una época (1985), así como al lingüista especializado en construcción de discursos Teun van Dijk. Cuando Van Dijk establece la tipología de maneras en que el discurso mayoritario representa el poder, especifica que el cine puede escenificar acciones y sus consecuencias, utilizando

3 En Global Wealth Report 2015, análisis del Credit Suisse, presentado a finales de 2015, se afirma que $1 \%$ de la población posee tanto patrimonio como el resto de la población mundial. 
herramientas para persuadir de la bondad o maldad de ellas, en busca de un efecto empático (2009, pp. 72 y ss.).

Para concluir esta primera parte, traeremos a colación la expresión con la que se etiquetó este conglomerado de ideas en la hegemonía desde finales de la década de 1970: el Nuevo Orden Mundial, expresión empleada por el delfín de Reagan, George Bush padre, durante un discurso (https:// goo.gl/qCDCBR). Algunos de los que lo impulsaban llegaron al absurdo respecto - siendo liberales - de llegar a apoyar a dictaduras frente a movimientos legítimamente democráticos y demócratas.

Según Bush y sus asesores, el libre mercado desregularizado había sido causa fundamental de la victoria sobre los soviéticos. Por tanto, tendría que ser uno de los ejes (si no el eje, como ha demostrado el tiempo), del Nuevo Orden Mundial, que aportaría un crecimiento infinito y una paz por aniquilación de los otros. ${ }^{4} \mathrm{La}$ crisis de 2008 significó una refutación de facto de esa promesa. La tecnocracia en su variante del Nuevo Orden Mundial no elimina los Estados, pero los subordina a ese fundamentalismo de mercado, "un sistema no normativo, controlado por los bancos, corporaciones y financiero" (Miller, 2005, p. 61).

El término Nuevo Orden Mundial se adecúa a nuestro propósito por la poca definición de sus límites y su inclusión de un espectro vastísimo de tendencias que lo utilizan, desde el ya citado del propio ultraliberalismo con Bush padre, a la crítica de izquierda (Chomsky), que invierte su carga y lo esgrime paródicamente contra Bush, a los grupos conspiranoicos.

\section{El pensamiento único hecho ficción, La invasión de los ultracuerpos}

Pocas películas escenifican este clima moral como La invasión de los ultracuerpos. Tanto el original de la década de 1950 como el remake de la década de

4 Una de las tesis fuertes de Fukuyama (2006). Se corresponde con una noción prevalente en el Estado totalitario: su naturaleza supuestamente eterna, el Reich de los mil años, que aparece implícito en la idea del fin de la historia por la contundente victoria de las democracias liberales (en el sentido que le otorgó Fukuyama). 
1970 comparten dicha lectura. Font subraya esa condición metafórica de los films de ultracuerpos respecto de la sociedad estadounidense (2012, pp. 42-45). Por su parte, Mann también alude a las referencias al miedo a perder los derechos en la población de la sociedad posterior a la Segunda Guerra Mundial (2004, p. 49).

En el film, basado en una novela de Jack Finney, se produce una invasión de una raza alienígena que duplica a los humanos para sustituirlos. Toda ella puede interpretarse como una alegoría que alerta contra el totalitarismo, con una duplicación de la realidad; la sociedad ultracuerpo se basa en arrasar cualquier tipo de diversidad, en la creación de una alter-humanidad que comparte un pensamiento único, sustituta de la humanidad de los deseos, las voluntades y las aspiraciones múltiples. Además, la nueva humanidad copiada por las vainas extraterrestres carece de sentimientos. Los totalitarismos "no se conforman con destruir la esfera pública, sino que tienen la pretensión de destruir lo humano, la esencia social de los ciudadanos, para que no exista en los hombres reserva alguna con respecto al poder” (Martínez, 2012, p. 125).

El peligro rojo de la Guerra Fría tomó fuerza durante la década de 1950 y concluyó en la década de 1980, por lo cual las doctrinas del nuevo economicismo a ultranza que adquieren el lugar predominante en los países occidentales son herederas del desarrollismo posterior a la Segunda Guerra Mundial, justo el periodo de mayor poder de los Estados Unidos en lucha dialéctica con la antigua URSS hasta su disolución a finales de la década de 1980. La ola de conservadurismo que intentó dominar la sociedad norteamericana a finales de la década de 1940 y principios de la década de 1950, con la comisión McCarthy como colofón totalitario, acabó sucumbiendo ante la generación del baby boom (en la adolescencia durante la década de 1950), que tomaría su relevo.

Pero ahondemos en las alegorías de los ultracuerpos. Ambas obras devienen grandes fábulas de la lucha contra el totalitarismo, pensamiento único monista impuesto al colectivo. Pero es que la gran valentía de ambos directores consiste en no proyectar el mal hacia el exterior, con las vainas 
que replican a comunistas, sino que lo dirigen al corazón estadounidense. Se trata de extrañas películas de horror sin monstruo, o cuyo monstruo es una humanidad sin humanidad. Otras obras de serie B de la década de 1950, como Invasores de Marte (Invaders from Mars, William Cameron Menzies, 1953), retratan esa misma desestabilización del mito familiar estadounidense, al situar la otredad inquietante en pleno corazón del hogar (Bou y Pérez, 2010, p. 109).

El remake de Kaufman está ambientado en San Francisco, mientras que el original de Siegel está ubicado en una pequeña comunidad rural del corazón norteamericano, un prototípico Santa Mira a medias un pueblo, a medias una ciudad, que tan solo podría existir en los Estados Unidos, hecha con los mimbres de Twin Peaks o Lumberton, el pueblecito donde transcurre Terciopelo azul (Blue Velvet, David Lynch, 1986). De hecho, Lynch sería el heredero de esa mirada de extrañamiento hacia la vida y lo colectivo estadounidense al tiempo que se comparte su código cultural. Hay mucho de los ultracuerpos en esa sospecha de que algo sórdido, algo profundamente siniestro, se agazapa bajo la idílica comunidad. Tras una postal de Norman Rockwell corretean insectos o vainas vegetales que pueden copiar a los humanos. Por sinécdoque, Santa Mira o San Francisco equivalen a la nación, de la que constituyen microcosmos. Con valentía, temeridad o inconsciencia, los dos cineastas alertaron sobre el inicio de ese núcleo irradiador totalitario, no en el extranjero, sino en el corazón de su país.

El proceso de copia del ser humano se produce durante la noche, mientras se duerme, frágil en su inconsciencia, con una vaina colocada al lado de la persona, de la que sorbe su identidad corporal, pero a la que vacía de aquello que la hace humana (https://goo.gl/Z8nXDP). Al día siguiente, cuando se despierta, ya forma parte del conjunto. Y los ultracuerpos carecen de elección. Según declaran personajes de la película, a primera vista, la sociedad de los ultracuerpos está bien, pero en realidad un extraño mal se ha apoderado de ella. ¿En qué consiste ese cambio? "Mi marido no es mi marido" será la sentencia más repetida en estas películas (https://goo.gl/HS5uhU). Los allegados aparentan ser ellos, hablan como ellos, pero no miran igual. 
En una secuencia que se repite en todas las versiones, uno de los personajes intenta convencer a otro, con el que le unía antes una relación íntima, de que se ponga a dormir sin recelar tanto. Cuando se despierte como ultracuerpo, no notará nada, recordará lo mismo, solo que formará parte de una comunidad que no es tal, una fuerza compuesta por una única voluntad y un pensamiento único. Los ultracuerpos se comportan igual, recuerdan lo mismo, pero se produce una casi inapreciable diferencia: las emociones se han evaporado (https://goo.gl/tGBTQa). Por tanto, podemos deducir de estos films que lo que hace humanos a los humanos no radica ni en la forma corporal, ni en los recuerdos, ni en un tipo u otro de estructura social, ni, por supuesto, en la armonía de sus relaciones: las emociones constituyen la esencia del ser humano en estos films.

Los extraterrestres pretenden sustituir a los humanos y sus organizaciones por otros seres aparentemente iguales, pero desangelados y sin personalidad propia. Más allá de la novedad impuesta a sus sociedades por los criadores industriales de nuevas vainas, en ambas versiones los replicantes aseguran que la sociedad seguirá igual, solo que será más eficiente al eliminarse las molestas emociones, el amor en primer lugar. ¿Cuántos desafortunados emparejamientos han provocado las flechas de Eros?

El protagonista de la versión original de Siegel es humano, porque ama e incluye entre sus características la de haber perdido, ya que lo abandonó la chica que amaba. En su capacidad para amar y perder, se halla la quintaesencia de su individualidad, el factor que lo humaniza. En cambio, los ultracuerpos no sienten nada y triunfan siempre. La victoria deviene única aspiración vital a la que supeditar los sentimientos. O directamente extirparlos. Uno de los postulados esenciales de la sociedad mediática de las últimas décadas radica en la creencia de que resulta imprescindible triunfar, y que uno mismo está llamado a esa victoria, en una sustentación del narcisismo del público.

A los ultracuerpos puede asignarse la siguiente descripción: "Es la encarnación perfecta de una entidad corporativa y burocrática —inhumana 
y desapasionada, conducida únicamente por la racionalidad" (Phillips, 2006, p. 54). ${ }^{5}$

En el nuevo orden social de las vainas, carece de importancia el destino de un miembro particular; lo único valioso se encuentra en el plan general, de ahí el totalitarismo monista, un orden basado en la dominación, en el aplastamiento de la insurgencia y en el autocontrol en sentido de la biopolítica. Se duplica el original para instaurar una directriz central inapelable, el pensamiento único como eje de las acciones (https://goo.gl/Masysb). Entre los ultracuerpos, no hay ni compasión ni crítica.

Tal vez el colmo de las acciones malvadas de los ultracuerpos consista en el descrédito absoluto de las explicaciones razonables; las primeras hipótesis de los doctores y psicólogos, tan sensatas, que achacan lo sucedido a una histeria colectiva, se revelan finalmente como una estratagema para ganar tiempo y asegurar la implantación absoluta de las vainas copiadoras. La verdad acaba dando la razón a las hipótesis conspiranoicas. ¿Cabe mayor perversión?

Las fábulas de ambas obras servirían como advertencias para evitar esa sociedad totalitaria, un poco a la manera del teatro de Brecht. Su descripción funciona como retrato social deformado, al menos en apariencia, de las sociedades occidentales tras la Segunda Guerra Mundial, que desembocan en la neoliberal de la década de 1980 . Se muestra el precio por pagar por una sociedad regida por el pensamiento único.

El final distinto de ambas versiones constituye una última cuestión respecto de la alegoría de los ultracuerpos en las dos películas, prueba del cambio cultural. Porque en esto las décadas de 1950 y 1970 sí se distinguen. En ambas, la ciudad escenario de la trama deviene finalmente totalmente ocupada por los ultracuerpos, quienes han creado finalmente el duplicado, una idea, la del simulacro de lo real, crucial en el fantástico posterior, pensemos, por ejemplo, en El show de Truman (The Truman Show, Peter Weir, 1998).

5 Is the perfect embodiment of the corporate / bureaucratic entity —inhuman and dispassionate, driven by rationality alone. 
Tanto Santa Mira como San Francisco quedan ocupadas. Una especie de fotocopia sin alma de lo anterior deviene la sociedad imperante. Ahora bien, la versión original de Siegel sufrió una de las maldiciones de las películas sobre la paranoia: como en El gabinete del doctor Caligari (Das Cabinet des Dr. Caligari, Robert Wiene, 1920), a la trama central se le superpone un prólogo y un epílogo que distorsionan por completo el tramo central, en la de Caligari para hundir la credibilidad del testimonio que ha narrado la historia; y en los ladrones de cuerpos para añadir un inverosímil final con esperanza. ${ }^{6}$ Los productores impusieron a Siegel ese final por motivos comerciales.

Pero en la década de 1970 la sociedad no era tan ingenua respecto de las fábulas y estaba preparada por un universo diegético tremendista. Por ello, Kaufman optó por quitar el ilógico epílogo, y eso que los finales angustiosos iban en contra del sistema canónico de los estudios: hay que hacer soñar a la audiencia. Por el contrario, los finales trágicos, sobre todo en las obras con contenido político —y los ultracuerpos lo tiene, por más disimulado que esté-, apelan a las audiencias a que reaccionen, al menos desde Brecht. Al optimismo de la generación del rock and roll lo sustituye un espíritu de derrota, aunque sin renunciar a la acción, típico de finales de la década de 1970, el punk.

La conclusión de La invasión de los ultracuerpos resultaba de las más duras en la historia del fantástico hasta ese momento: toda la sociedad replicada y la última de las disidentes descubierta y señalada por el doble sin emociones de su amigo y antiguo compañero de rebeldía (https://goo.gl/ BtaLAr). It's morning in America. Los ultracuerpos vinieron en la década de 1950 para quedarse. Visto desde la perspectiva de 1978, con el ultraliberalismo haciendo sus primeras incursiones y el amanecer prometido por Ronald Reagan que se dibujaba en el horizonte, el vaticinio resultaba tan amenazador como acertado.

6 El final pensado por Siegel tenía que ser la secuencia del desesperado protagonista en la autovía, presagiando a los conductores que se detienen que ellos serán los siguientes (Font, 2012, p. 44); también se refieren a lo forzado del epílogo Bou y Pérez (2010, p. 101), Balló y Pérez (2011, p. 80) y Loock (2012, p. 134-137) (https:// goo.gl/ziBLtG). 


\title{
Los ultracuerpos toman el fuerte, Secuestradores de cuerpos
}

\begin{abstract}
A principios de la década de 1990, Abel Ferrara dirigió otra película sobre el universo de las vainas replicadoras, Secuestradores de cuerpos. No extraña que así lo hiciera, ya que el cineasta pensaba: "Un film como La invasión de los ladrones de cuerpos debería ser rehecho cada año para dar cuenta de las mutaciones del tiempo" (Font, 2012, p. 552, n. 13), afirmación compartida por el autor del presente artículo, como ya se ha indicado.
\end{abstract}

En este caso, el director modificó el escenario de la función y varió parcialmente el tema principal tratado, por lo cual no mantiene demasiada relación con las otras secuelas; su único vínculo se encuentra en la existencia de las vainas, cuyo plan de dominación global implica una mutación completa de la humanidad, pero Ferrara optó por no analizar tanto las implicaciones sociales de ello; en su lugar, trazó un cuento macabro sobre los temores de adolescentes a lo que implica la madurez. El trasfondo social cedió su lugar a lo psicológico. Loock, incluso, señala que el film mezcla la película de terror con el melodrama familiar (2012, p. 133).

Una parte significativa de las películas de fantástico también pueden leerse bajo ese prisma de fantasmagoría de la psicología profunda, por ejemplo como escenificaciones de los temores infantiles y adolescentes al sexo, tema que resuena también en los ultracuerpos, que ni se emocionan ni aman, y se reproducen como los vegetales.

La voz de la narradora y protagonista abre y cierra el círculo de la narración y le aporta un grado de subjetividad que resalta la importancia de su personaje, no solo como protagonista, sino como filtro de lo narrado. De ahí el tono de sombras chinescas de lo subconsciente adquirido por el film. Con ese inicio, se sitúa la historia como si se tratara de un recuerdo suyo.

La adolescente se dirige a un cuartel militar al que ha sido destinado su padre científico, quien ha de tomar muestras del lugar y analizarlas, ya que en la base se experimenta con armas biológicas. Además de a la adolescente y a su padre, también los acompañan el hermano pequeño y la ma- 
drastra. Según da a entender la chica, no está muy de acuerdo en pasar un verano en lugar tan poco estimulante ni de aprobar el nuevo matrimonio de su padre, que permite la aparición de la madrastra, personaje de participación tan tradicional en los cuentos de hadas.

El género fantástico utiliza a menudo este mismo esquema de dos tramas paralelas y dependientes, una de tipo realista, con un conflicto social o psicológico en tela de juicio, al tiempo que la segunda línea, la propiamente fantástica, se le superpone y a menudo actúa como una especie de reflejo simbólico de la primera.

El doctor de la base le pregunta al científico si unos productos que tal vez hayan sido vertidos pueden desencadenar procesos paranoicos, los ya conocidos por las obras de Siegel y de Kaufman, como la conducta insólita de ciertas personas, la duda de sus familiares a que se traten de las mismas personas, el temor a dormir, y otros detalles inquietantes.

Las dos primeras obras, más esta, forman un tríptico de clásicos sobre la paranoia. En ese sentido, anuncian la nueva sensibilidad de sospecha hacia lo real. Es más, y a título de anécdota, como ya se ha indicado, en todas ellas aparecen psiquiatras; los confusos y angustiados protagonistas se dirigen a ellos en busca de respuestas, pero, más que orientarlos, los desorientan. "La idea de los ladrones de cuerpos está tan condicionada a la paranoia colectiva que es normal que los psiquiatras se sitúen en lugares clave para la organización dramática del film" (Bou y Pérez, 2010, p. 110). De hecho, son de los primeros en ser replicados por los ultracuerpos e intentan tentar a los respectivos protagonistas para que se unan a la nueva sociedad en el mundo feliz, sin dudas, frustraciones o conflictos. La naturaleza del ultracuerpo.

Respecto del núcleo familiar, la primera en cambiar es la madrastra, claro está, lo cual lleva el conflicto íntimo y realista de la familia al extremo (https://goo.gl/YWh7rr). Como en toda buena película fantástica, ese film está plagada de símbolos visuales que pueden entenderse como escenificaciones de procesos psicológicos, desde accesos a subterráneos con monstruos agazapados en ellos, hasta ascensiones por escaleras para liberarse. 
Los cambiados empiezan a comportarse de manera inusual, en lo que daría la impresión de ser aspectos positivos, como los alcohólicos dejar de emborracharse (como los copiados no beben, los bares se vacían), un poco a la manera de una antropología new age, pero en realidad indicativo de la muerte de su personalidad tanto en la faceta social como en la individual.

Ferrara demuestra su talento en planos de gran carga expresiva, expresionistas, que trasladan a lo formal la mirada alucinada de la trama paranoica. Descuella también en ideas originales para secuencias, como esa en que una profesora de guardería ya replicada por las vainas certifica qué niños han cumplido el proceso y cuáles no al observar sus dibujos. Pese a ello, la melodramatización excesiva y algunos deus ex machina inverosímiles impiden que esté a la altura de las dos predecesoras. El director resaltó el factor de la nueva carne (https://goo.gl/CLepb1) al mostrar mucho más que sus predecesoras la transformación. El viejo cuerpo consumido por las vainas termina en bolsas de basura, en un hallazgo visual digno de un gnóstico.

Otro cambio significativo consiste en la casi total ausencia de secuencias de transición entre una sociedad humana a la replicada, puesto que en una única noche se desencadena todo; se hace visible la invasión hasta entonces sutil. Se produce una contienda en la que los humanos tienen todas las de perder (https://goo.gl/DFo4Tx). Para subrayar que con la trama se ahonda en niveles de psicología profunda, que trata de un viaje metafórico a las pulsiones de la protagonista, la hija mata al padre y al hermano pequeño al advertir que ya no se trata de ellos. De hecho, con el padre se crea una incertidumbre sobre si ha acertado en su apreciación, aunque al morir demuestra tratarse de un engendro copiado por una vaina.

Uno de los personajes, el militar médico de la base, tras tomarse gran cantidad de anfetaminas de su dispensario, quiere enfrentarse a tiros, en una explosión de violencia como estrategia para sobrevivir. En una resolución compartida con muchas de las películas de zombis, el militar se suicida finalmente, ya que se niega a ser copiado por las vainas (https://goo. gl/QtE63Q). 
Los dos últimos supervivientes, la adolescente y su novio piloto, también reaccionan violentamente; atacan a bombazos la base y los camiones que pretenden distribuir las vainas por todas las bases del ejército norteamericano (sarcástico Ferrara), en una reacción de venganza, completamente humana, según afirma la voz superpuesta de la protagonista. Con todo, sigue la tendencia pesimista del remake de la década de 1970. ¿Cómo no iba a ser así? A principios de la década de 1990, se había consolidado enormemente el mundo que había empezado a vislumbrarse en la década de 1970. Del amanecer en América se había pasado al mediodía, según la metáfora axial de esta propuesta.

Ahora bien, en esta obra, se tiende más a la lectura psicológica que a la social. Con la eliminación de la madrastra, el padre superprotector y el hermano pequeño pesado, antes de poder volar con su novio piloto, la adolescente ha cumplido con su rito de paso hacia la vida adulta, lo cual comporta cierto grado de conformismo. Tal vez el consenso no sea tan negativo: quizá sea incluso algo tan humano como madurar. La película hace mucho más evidente el subtexto en clave sexual, sobre las consecuencias de una madurez en la que se apaga la pasión del amor de pareja (Bou y Pérez, 2010, p. 106).

Así, justo tras el vuelo liberador con el joven topgunero — toda la película ironiza sobre el tópico del aviador irresistible, tipo top gun (Tony Scott, 1986) - y sus lanzamientos de bombazos, la pareja se reintegra en la sociedad, ya eliminados los rasgos de rebeldía adolescente. Secuestradores de cuerpos juega con los estereotipos sexuales de aquella época, el intrépido aviador, la adolescente enamorada, pero lo hace como es propio del fantástico, de forma encubierta por metáforas, hasta su irónico final, en el que se suman a los ultracuerpos como matrimonio desangelado. Un poco el mismo camino ya emprendido por la protagonista de Lolita, tanto la novela de Nabokov como el film (Lolita, Stanley Kubrick, 1962). Tras ese tránsito ya son como los demás. Con su inclusión en el círculo social de los adultos - ultracuerpos-, concluye la película. 


\section{La película ultracuerpo, Invasión}

Las diversas fases del cine comercial norteamericano quedan fijadas en las cuatro obras sobre los ultracuerpos, diversos sustratos que evidencian un progresivo empobrecimiento de la veta del clasicismo y el sistema de estudios. En este caso, resulta notorio, al menos para quien esto escribe, que si los remakes de la década de 1990 podían llegar a ser pertinentes desde un punto de vista artístico, con creadores como Ferrara innovando, desde entonces, con la era de los blockbusters, responden a causas comerciales, en un empobrecimiento de la faceta artística, que va del mito del hombre musculoso de las películas de acción de la década de 1980 a los blockbusters de fantástico en la década de 1990, según Gimello-Mesplomb (2007). Invasión forma parte de esa corriente de sucedáneos de películas de serie $\mathrm{B}$ de la década de 1950, producidas con grandes presupuestos y con actores famosos, contratados por millonadas y con una participación en los ingresos, cuando no directamente productores.

Una emoción blanda inunda los productos blockbuster: en una película para todos los públicos hecha a la manera del Hollywood actual, difícilmente morirá ninguno de los protagonistas ni de sus seres queridos. De hecho, en el plano de lo visible socialmente, no se puede morir ni perder. Según el ideario social hegemónico a principios del siglo XXI, el fracaso estaba prohibido, y fallecer no es más que el más grande de los fracasos. Al no mostrarlo la cámara, deja de existir. Con la crisis de 2008, se desmoronó este tipo de mentalidad.

Además, la película sirve para potenciar el pensamiento hegemónico del periodo. Las formas de arte popular sirven para abonar el terreno de ciertas ideas interesantes para el poder y generan un contexto apropiado, en un proceso de construcción de mentalidad mediante el discurso público de larga tradición. El analista de elaboración de discursos Van Dijk considera a quienes participan en la creación como la élite simbólica, y reflexiona:

Habitualmente el poder social es indirecto y opera a través de la "mente" de las personas, por ejemplo, mediante el manejo de la información o las opiniones necesarias que requieren las personas para planificar o ejecutar sus acciones. La mayoría de las formas de 
poder social que se ejercen en nuestra sociedad implican este tipo de "control mental", que por lo general se consigue por intermedio de la persuasión u otras formas de comunicación discursiva [...]. En este punto, adquiere particular pertinencia nuestro análisis del rol del discurso en el ejercicio, es decir, el mantenimiento o la legitimación del poder. (2009, p. 62)

En esta ocasión, la protagonista ejerce directamente de psiquiatra, papel relevante en las anteriores versiones, según ya se vio más arriba, pero que nunca había intervenido en este rol principal, factor indicativo en un código narrativo tan personalista y focalizado como el de Hollywood. El personaje se declara feminista posmoderna, progresista convencida de que cree en la evolución que mejora la especie.

Se sustituye el amor entre adultos de las dos primeras versiones — de pareja en la década de 1950, fraternal en la década de 1970 — por la unión materno-filial como último bastión de lo humano. Rasgo este también completamente insertado en las nuevas tendencias de blockbusters. Se trata del amor más resistente, a juzgar por sus efectos, así como del más rentable en taquilla, con un tipo de público ideal mucho más amplio, que abarca tanto a la infancia como a los padres. En el lenguaje del marketing, mejor dos targets que uno. Y el espectador descubre otra característica de los ultracuerpos: además de no replicar lo emocional, tampoco duplican lo instintivo; de hecho, lo animal desconfía de ellos, y los perros se avanzan a los humanos en captar la diferencia.

En varios momentos de la trama en segundo plano o incluso en primero, se colocan fragmentos de telenoticias que hacen avanzar la historia y situarla en el marco de las infecciones contagiosas. Aunque la obra muestra de telón de fondo conflictos sociales y psicológicos, estos no presentan jamás la hondura que en sus predecesoras. A diferencia de en las otras versiones, los organismos oficiales descubren lo que sucede y, en zonas como Europa o Japón, han declarado la epidemia, pero no en los Estados Unidos. It's morning in America. Se acentúa la desconfianza hacia las fuerzas del orden. De hecho, como en las versiones previas, las fuerzas oficiales luchan contra los humanos, los detienen para transmitirles el virus, una desconfianza hacia la autoridad prototípica de la sociedad de la sospecha conspiranoica. 
Pronto la trama deriva en persecuciones, espectáculo de atractivos colores en movimiento, muestra de cine de atracciones, confeccionado para lucimiento de la estrella. Gracias a Invasión sabemos que una psiquiatra sabe manejar su vehículo con la pericia de piloto profesional (https:// goo.gl/KmfK2X), disparar con precisión de campeón olímpico de tiro o ser veloz en sus huidas para escapar de decenas de perseguidores pese a correr sobre tacones casi de aguja. El código institucional en Hollywood con sus héroes carismáticos, patentado en la meca del cine ya desde sus orígenes, alimenta el narcisismo del público, que puede identificarse con personajes retratados con aparente realismo, pero, en realidad, superhéroes de poderes paranormales $y$ de triunfo seguro.

Así, el espectador que se identifique con ellos - y el éxito de público de estas superproducciones invita a pensar que son muchos los que disfrutan con ello- llega a persuadirse de que los conflictos pueden resolverse de esa manera, con una psiquiatra que a su vez parece piloto de Fórmula 1 , posee dotes militares y sabe manejar armas, además de experta karateka cuando lo requiere la ocasión. La pantalla nos enseña que alcanza antes un lugar una madre que sube un rascacielos por un ascensor que un helicóptero a pocos metros de la azotea. Ningún milagro se resiste a la moderna industria del espectáculo.

Invasión se separa de las versiones previas justamente por el componente infeccioso; algunos humanos resultan inmunes al contagio, decisión mediante la cual se evita un final pesimista, imposible según los cánones de las grandes producciones. Como en Contagio (Contagion, Steven Soderbergh, 2011), los buenos científicos se ponen a investigar en unos laboratorios y van a dar con toda certeza con una vacuna infalible para la pandemia por virus extraterrestre. De manera inverosímil, a los ultracuerpos no se les ocurre lanzar un ataque devastador contra el centro de investigación humano, pese a que casi emiten en directo sus investigaciones. Según parece, el pensamiento único puede conquistar el mundo en veinticuatro horas, pero no resolver la más simple de las complicaciones.

Pero es que la superproducción no podría finalizar con un panorama desolador. Al público se le ha de ofrecer ilusiones. Invasión vuelve a probar 
que en casi todas las ocasiones los finales felices propuestos por la gran industria cultural resultan una invitación al conformismo, mientras que un final pesimista puede hacer pasar un mal trago al espectador, pero quizá lo invite a reflexionar de manera más profunda a propósito de su entorno. En ocasiones, un final de derrota cinematográfica puede resultar en una victoria en el mundo de referencia o, al menos, ayudar a comprenderlo más profundamente.

\section{Conclusión}

Con el remake ultracuerpo de los ultracuerpos, se concluye este kracaueriano juego de reflejos entre la sociedad occidental posterior a la Segunda Guerra Mundial y la construcción de un imaginario en la que aparezca representada, en este caso de una manera deformada, la propia del género fantástico cinematográfico, con uno de los motivos argumentales más señeros de las últimas décadas.

Pero antes de terminar, conviene matizar algunas cuestiones. En su reflexión sobre los totalitarismos, Arendt excluye explícitamente el capitalismo de tal condición, al sostener que solo se han conocido dos estados de esa clase: el nazi desde 1938 y el bolchevique desde 1930 (1979, p. 419). Y tiene razón: no puede imputarse tal cosa al capitalismo en el periodo en el que vivió Arendt. Pero es que incluso el tipo de régimen con Reagan o Thatcher no puede compararse con el nazismo o el estalinismo, excepto si uno cae en el exceso retórico-ideológico o, como es el caso, en términos de metáfora fantástica, es decir, como pesadilla estética que en ningún caso pretende adjudicarse las herramientas de una argumentación lógica en términos racionales.

Lo que sí puede conseguir un film es crear una fantasía que muestre tendencias de época, que elabore un imaginario revelador de tendencias, deseos y temores. Y en esa construcción de imaginario, dentro de su horizonte cultural y del tipo de persuasión que manejó, sí que el ultraliberalismo aspiró a un monismo intelectual, ejemplificado por la constante aseveración de una carencia de alternativas, así como en la toma de decisiones realizada en instancias externas a las del Gobierno y el Estado (instancias económicas). 
Es, por tanto, en esa elaboración de un horizonte cultural que construye marcos simbólicos, no en el discurso argumentativo filosófico, donde opera la fábula de los ultracuerpos, como toda ficción.

No pretende, pues, con ello devenir un retrato más o menos genuino en términos naturalistas: huye de lo literal, sustituido por lo simbólico y la distorsión, lo onírico que traslada al espectador a una pesadilla. Hay que tener en cuenta el factor de que las cuatro películas pertenecen al fantástico terrorífico, de manera que, necesariamente, han de buscar facetas de extrañamiento y de pavor, exagerando la cuestión al máximo. No hay lugar a los matices o los análisis ponderados, ni se trata del medio adecuado para ello. El mundo referencial jamás alcanza el grado de las metáforas, afortunadamente. $Y$ este artículo ha pretendido mantenerse en ese estrato, no en el efectivo, la "realidad", en el que solo desorbitando tremendamente la comparación se podría afirmar que el ultraliberalismo ha sido totalitario.

Es más, por poner en tela de juicio mi argumentación, pueden ofrecerse algunas razones que explican esa elección de una sociedad de consenso, que la justifican, o que incluso la contradicen. Por ejemplo, puede aducirse que, lejos de los temores sobre los ultracuerpos, la sociedad de las últimas décadas ha sido enormemente plural, cosa probablemente cierta, aunque quizá no fue esa la impresión que se deseó transmitir desde la élite intelectual que construyó el discurso hegemónico. De la misma manera, es más que posible que un mundo que dispone de armas nucleares deba buscar consensos en ciertos asuntos capitales para no autodestruirse; un armamento de tal calibre aconseja extremar la prudencia, incluso a riesgo de perder ciertos matices. Pero es que hay que huir del literalismo: los ultracuerpos no pretenden convertirse en mapa del mundo, sino facilitar el escenario de un sueño, escenificar con una fantasía, pero para que revele aspectos ocultos de la realidad. En definitiva, se dirige más a lo cultural que a lo político.

Además, la trama simbólica crítica con el totalitarismo no es la única en estas películas, como ya se comentó en Secuestradores de cuerpos; pueden introducirse muchos otros subtemas más psicológicos, como el miedo a la madurez y a la sexualidad de una adolescente, según se comentó más 
arriba. Por ello, tampoco resulta necesariamente la única lectura que puede realizarse. La exégesis permanece abierta a otros hermeneutas con formas diferentes de interpretarla.

Según se ha confesado al inicio, la propuesta de este artículo pretendía, no solo explicar algunos de los puntos básicos de las cuatro películas, sino ponerlas en el contexto social de los últimos setenta años, desde la década de 1950 en la cultura dominante en Occidente (Estados Unidos), hasta la posmodernidad tardocapitalista justo antes de la crisis. Se ha especificado ese término no en el presente, porque justamente los cambios que han acontecido en la última década aconsejan volver a poner el termómetro a los temores del presente con una nueva versión de los ultracuerpos. ¿Qué aparecería en el remake actual? ¿El final de la amenaza totalitaria o la conquista definitiva de los ultracuerpos?

Cada lector es libre de plantear una respuesta personal.

\section{Referencias}

Arendt, H. (1979). The origins of totalitarianism. San Diego: Harcourt Brace Jovanovich Publishers.

Balló, J. y Pérez, X. (2011). La semilla inmortal: los argumentos universales en el cine. Barcelona: Anagrama.

Bou, N. y Pérez, X. (2010). Invasion of the Body Snatchers: silenciadores de cuerpos. En Q. Casas y A. C. Iriarta (eds.), Don Siegel (pp. 99-114). San Sebastián, Madrid: Donosita Zinemaldia, Festival de San Sebastián, Filmoteca Española.

Chomsky, N. (1996). El nuevo orden mundial (y el viejo). Barcelona: Crítica.

Chomsky, N. (2006). El control de los medios de comunicación. En N. Chomsky e I. Ramonet, Cómo nos venden la moto: información, poder y concentración de medios (pp. 7-54). Barcelona: Icaria. 
Dijk, T. A. van (2009). Discurso y poder: contribuciones a los estudios críticos del discurso. Barcelona: Gedisa.

Font, D. (2012). Cuerpo a cuerpo: radiografías del cine contemporáneo. Barcelona: Círculo de Lectores.

Foucault, M. (1985). Las palabras y las cosas. México: Siglo XXI.

Fukuyama, F. (2006). The end of history and the last man. Nueva York: Free Press.

Gimello-Mesplomb, F. (2007). Le cinema des anys Reagan: un modèle hollywoodien. París: Nouveau monde éditions.

Harvey, D. (2009). Breve historia del neoliberalismo. Madrid: Akal.

Hendershot, C. (1999). Paranoia, the bomb, and 1950s science fiction films. Bowling Green: Bowling Green State University Popular Press.

Kracauer, S. (1985). De Caligari a Hitler: historia psicológica del cine alemán. Barcelona: Paidós.

Kuhn, A. (1992). Introduction: Cultural theory and science fiction cinema. En A. Kuhn (ed.), Alien zone: Cultural theory and contemporary science fiction Cinema (pp. 1-12). Londres: Verso.

Loock, K. (2012). The return of the pod people: Remarking cultural anxieties in Invasion of the Body Snatchers. En K. Loock y C. Verevis (eds.), Film remakes, adaptations and fan productions: Remake/remodel (pp. 122-144). Palgrave Macmillan: Basingstoke.

Mann, K. (2004). You're Next! Postwar hegemonic besieged in Invasion of the Body Snatchers. Cinema Journal, 44(1), 49-68.

Martínez Lucena, J. (2012). Ensayo Z: una antropología de la carne perecedera. Córdoba: Berenice. 
Miller, T. (2005). El nuevo Hollywood: del imperialismo cultural a las leyes del marketing. Barcelona: Paidós.

Phillips, K. R. (2005). Projected fears: Horror films and American Culture. Westport: Praeger.

Ramonet, I. (2006). Pensamiento único y nuevos amos del mundo. En Chomsky, N. e I. Ramonet, Cómo nos venden la moto: información, poder y concentración de medios (pp. 55-98). Barcelona: Icaria.

Scruton, R. (2007). The Palgrave Macmillan dictionary of political thought. Nueva York: Palgrave Macmillan.

Shorrocks, A., Davies, J. y Lluberas, R. (2015). Global Wealth Report 2015. Research Institute. Recuperado de http://ep00.epimg.net/desca rgables/2015/10/14/81 cef5bbe2878e321682f7adfde25ec6.pdf

Veiga, F. (2009). El desequilibrio como orden: una historia de la posguerra fría. 1990-2008. Madrid: Alianza. 